\title{
THE MOODY CHAMELEON: THE EFFECT OF MOOD ON NON-CONSCIOUS MIMICRY
}

Rick B. van Baaren

University of Nijmegen

Daniel A. Fockenberg

Free University Amsterdam

Rob W. Holland, Loes Janssen, and Ad van Knippenberg University of Nijmegen

Whereas previous findings suggest that mood alters information processing style judgment and strategic behavior, in the present article, the hypothesis is tested that moods influence our non-conscious behavior. In the first study, we observed a correlation between participants' mood and their non-conscious mimicry of a person on television. In the second study, participants were put in either a positive or negative mood and afterwards they watched a video comprising of two episodes, one with a pen-playing experimenter, and one with a non-pen-playing experimenter. Participants were videotaped to see whether they would mimic the pen-playing experimenter. As predicted, we found that only participants in a positive mood mimic the confederate's behavior. Finally, tentative evidence suggesting that the effect of mood on mimicry is mediated by cognitive processing style is discussed. These results support a functional explanation for the effects of mood on information processing and behavior.

Mood has a profound effect on information processing and judgements. When we are in a positive mood, we tend to rely on existing knowledge structures, such as stereotypes (Bodenhausen,

Address correspondence to Rick van Baaren, Department of Social Psychology, University of Nijmegen, PO Box 9104, 6500 HE Nijmegen, The Netherlands; E-mail: r.vanbaaren@psych.ru.nl. 
Kramer, \& Süsser, 1994) and scripts (Bless, Clore, Schwarz, Golisano, Rabe, \& Wolk, 1996) to a greater extent than when we are in a negative mood. Although there are several competing accounts for the effects of mood on processing (see Forgas, 2002, for a review), a functional explanation for these findings is suggested by Schwarz and colleagues (Clore, Gasper, \& Garvin, 2001; Schwarz, 1990; Schwarz \& Bohner, 1996; Schwarz \& Clore, 1996). In this explanation, moods (or diffuse affective states) serve as a signal, conveying information about the friendliness of our environment. This explanation is based on Jackobsen's (1957) view of mood as a "barometer." A positive mood signals that the environment is safe and unproblematic, whereas a negative mood indicates potential problems. These signals subsequently influence our information processing and judgements. When we are in a positive mood, our environment seems to pose no threat and we are more likely to rely on heuristic (Bless et al., 1996; Bodenhausen, Kramer, \& ,Süsser 1994) and creative processing (Bless, Bohner, Schwarz, \& Strack, 1990; Bodenhausen et al., 1994). In contrast, a negative mood signals that the environment is problematic and that therefore one needs to be on guard, resulting in an information processing style that is relatively analytical, effortful, and cautious (Bless, Mackie, \& Schwarz, 1992; Bodenhausen et al., 1994; Schwarz \& Bless, 1991; Schwarz \& Clore, 1996). In sum, a positive mood elicits a more holistic and less analytic way of perceiving and processing information about the environment than a negative mood.

Furthermore, research has shown that moods not only influence our information processing, but also our strategic behavior (see Forgas, 2002). As Forgas describes:

Affective states influence interpersonal behaviors because of their influence on individual cognitive processes. In several experiments we demonstrated that mild mood states influence the way people think about, plan, and execute strategic interactions, the way they formulate and respond to requests, and the way they perform in bargaining tasks. (Forgas, 2002, p. 94)

Something is missing, however. The functional explanation of mood effects can hardly be called functional when it depends on conscious cognitive effort, or when it only influences conscious 
and strategic behaviors. For moods to be truly functional, given the extremely complex environment we live in and interact with, they should (a) be capable of non-conscious activation and (b) influence our implicit cognitions and implicit or non-conscious behavior. Evidence for the hypothesis that moods can be non-consciously influenced comes from recent work by Chartrand, Van Baaren, and Bargh (in press), which indicates that subliminal exposure to either positive or negative words induces corresponding mood states and information processing style, that is, better moods and more heuristic processing after subliminal exposure to positively valanced words compared to negatively valanced words. These results suggest that our moods do automatically inform us about the status of our environment. For this to be functional, however, moods should also influence our automatic behavior.

In this article, we propose that mood affects our non-conscious behavior. As argued above, in a negative mood, people process information more effortful and tend to be more analytic, whereas a positive mood is associated with less effortfully and hence, more automatic, processes. By the same token, a negative mood should induce cautious behaviors, that is, to "think before one acts," while a positive mood may facilitate spontaneous, automatic behavioral tendencies, that is, "to act on impulse." From the same general functional perspective, then, it can be argued that mood will also affect non-conscious behavior. Specifically, it is hypothesized that in a positive mood, people will more easily adopt automatic behaviors than in a negative mood.

One of the purest forms of automatic behavior is mimicry (Chartrand \& Bargh, 1999; Van Baaren, Horgan, Chartrand, \& Dijkmans, 2004; Van Baaren, Maddux, Chartrand, De Bouter, \& Van Knippenberg, 2003). Recent research by Chartrand and Bargh (1999) convincingly showed that mimicry occurs automatically and even among strangers. In this research, participants interacted with an unknown confederate in two consecutive picture-describing sessions. In one session, the confederate either rubbed her face or shook her foot while describing the pictures with the participants, while the second confederate performed the behavior that the first confederate did not. The behavior of the participants, recorded on videotape, showed that participants 
shook their foot more in the presence of the foot-shaking confederate, and rubbed their faces more in the presence of the face-rubbing confederate. Debriefing indicated that participants were unaware of their mimicry.

In the present research, we assessed the effect of mood on non-conscious mimicry. In Study 1, we focused on the correlation between naturally occurring differences in mood states and non-conscious mimicry. In Study 2 the influence of mood on non-conscious mimicry was studied using an experimental manipulation of mood.

\section{STUDY 1}

\section{METHOD}

Participants. Fifty-eight undergraduate female students from the University of Nijmegen were paid for participation in this study.

Procedure. Participants first filled out a questionnaire including a mood adjective list. This list consisted of three items on bipolar 7-point scales, asking for the extent that participants felt good-bad, happy-sad, and joyful-gloomy (alpha $=.76$ ). Afterwards, the experimenter instructed the participants to watch a 5-minute video, showing an actor conducting a series of clerical tasks (e.g., making a telephone call, writing in a diary, see Van Baaren et al., 2004, Study 1). In addition to these tasks, the actor also rubbed his face several times (e.g., Chartrand \& Bargh, 1999). No other behaviors than the clerical tasks and the face rubbing were shown. When the experimenter had started the video she left the room, leaving the participant alone. The behavior of the participants was secretly observed by a camera. The number of times that the participant rubbed his face as well as the amount of time that each participant rubbed her face was secretly observed by a camera and served as our measure for mimicry. Finally, participants were thanked, debriefed, and dismissed.

\section{RESULTS AND DISCUSSION}

The face rubbing on the videotapes was coded by a judge and 10 participants were randomly checked by a second, independent 
judge. The data from the first participant was judged by both judges, so they would agree on the criteria. The interjudge reliability was very high, both for the number of times the participant rubbed her face $r(9)=.97$, as for the amount of time she rubbed her face, $r(9)=.99$.

A positive correlation was found between mood and the number of times that the participant rubbed her face, $r(55)=.26, p=.05$, as well as a positive correlation between mood and the amount of time that the participant rubbed her face, $r(55)=.28, p<.05 .{ }^{1}$ These results are consistent with our general prediction: the more positive an individual's mood state, the more this individual mimics the behavior of the person on the television.

Because of the correlational nature of our first study, we decided to run a second study. In Study 2, we investigated the effects of mood on non-conscious mimicry, by using an experimental manipulation of mood.

\section{STUDY 2}

\section{METHOD}

Overview. Participants first watched a movie clip that either induced a positive or a negative mood. Then they watched a video, which consisted of two sessions. In one session an experimenter either played or did not play with a pen, in the other session another experimenter did the opposite. Participants were secretly videotaped to test whether they mimicked the pen-playing behavior displayed on the TV screen.

Participants and Design. Thirty-five undergraduate students (8 male and 27 female) from the University of Nijmegen were paid for participation in this study. The experiment had a 2 (Mood: positive or negative) $\times 2$ (Behavior: pen-playing or control) mixed design with repeated measure on the second factor.

Procedure. Upon arrival at the laboratory the participant was led into the experimental room, where the experimenter then explained that the participant would have to perform several unrelated tasks, and turned on the video for the first task.

1. Three participants had mood scores that deviated more than $2.5 S D$ from the mean and were therefore excluded from the analysis. 
The first task was the mood induction. In both conditions participants watched a film clip of approximately 6 minutes. In the positive condition the clip was a compilation of $M r$. Bean sketches, a funny TV show, whereas in the negative condition, the film clip was a scene from Sophie's Choice. In a pilot study, these clips were successful in inducing the corresponding moods. Thirty-three participants watched either Mr. Bean or Sophie's Choice and immediately thereafter their moods were assessed. The mood measurement consisted of two bipolar 7-point scales $(\alpha=.89)$, with each scale-end corresponding to a specific feeling (good-bad, happy-sad). Results indicated that participants who watched Sophie's Choice were in a negative $\operatorname{mood}(M=3.11)$, and participants who watched $M r$. Bean were in a positive mood $(M=5.70)$, $t(1,31)=-8.14, p<.001$.

After this mood induction, the experimenter reentered the room and started the second videotape. The participant was told that this was a new and unrelated study on music and preferences. On this tape a "music task" was presented, in which participants had to listen to pieces of music that an experimenter on the TV screen ostensibly started. The task consisted of two sessions. Within each session two music fragments of two- and-a- half minutes were played. Two experimenters were used and each experimenter appeared in one session of the videotape. In one session the experimenter would play with a pen, in the other session the experimenter would not play with a pen. It's important to note that participants were alone in the room and the actor/experimenter appeared on the TV screen. The pen playing occurred three times a minute for 10 seconds and in the control session, no pen playing occurred at all. Participants were videotaped to see whether they imitated the pen-playing behavior of the experimenter on the TV screen. Experimenters and behaviors were counterbalanced.

RESULTS AND DISCUSSION

Non-Conscious Behavior Measure: Mimicry. ${ }^{2}$ The interjudge reliabilities for pen-playing was satisfactory, $r=.69$. No effects of coun-

2. Two participants had mimicry scores that deviated more than $2.5 S D$ from the mean and were therefore excluded from the analysis. 
terbalancing were observed (all $F^{\prime} s<1$ ), so the data were collapsed. The number of times the participants played with a pen was subjected to a 2 (mood: positive or negative) $\times 2$ (behavior: pen playing or control) mixed model analysis of variance (ANOVA) with repeated measures on the second factor. The only significant effect was the expected mood $\times$ behavior interaction, $F(1,31)=6.29, p<$ .02. Simple effect analyses confirmed that participants in the positive mood condition played with a pen significantly more when the experimenter played with his pen $(M=2.41)$ than when the experimenter didn't play with his pen $(M=0.93), F(1,31)=7.02, p<$ .02. No such effect emerged in the negative mood condition $(M=$ 1.47 and $M=1.23$, respectively), $F(1,31)=.85, n$ s (see Figure 1 ).

\section{GENERAL DISCUSSION}

The present research found evidence for the automatic behavioral consequences of mood. First, in Study 1 we obtained a positive correlation between mood state and the non-conscious mimicry of the behavior of others. Study 2 replicated this effect using an experimental manipulation of mood. To our knowledge, this is the first evidence for an effect of mood on automatic behavior.

These findings support a functional explanation of the effects of mood on processing and action. Moods give us information about the status of our environment and we subsequently adjust our cognitive processes in a manner that is best suited for the situation; holistic when we feel good and things are going okay, and analytic when we feel bad and things are problematic. The present research is the first to show that we even adjust our non-conscious behavior to the environment. In a good mood, we automatically take over the behavior of others, whereas in a bad mood, we are less easily influenced by other people's behavior.

In addition, it is important to realize that in both studies, the target person was presented on a TV screen and participants were alone in the room. There is no logical or strategic reason for participants to mimic the behavior of the experimenter. Although happy moods have been known to foster smooth social interactions (George, 1990), in the present studies, there was no interaction. Participants must have been unaware of their mimicry (see also Chartrand \& Bargh, 1999; Van Baaren et al., 2003; Van Baaren 


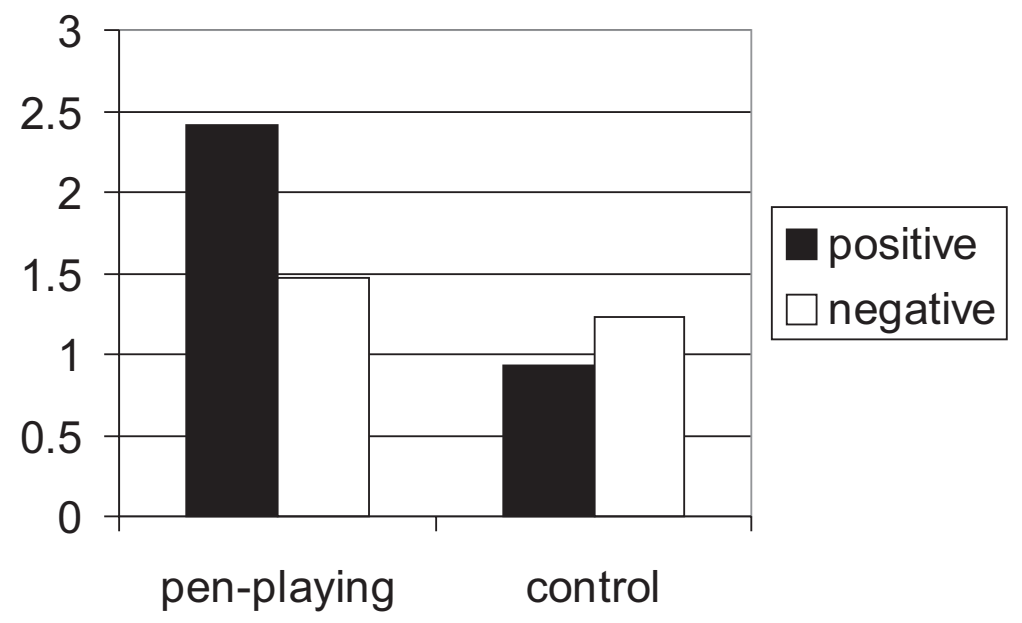

FIGURE 1. Amount of pen-playing during pen-playing or control video session in the positive and negative mood conditions.

et al., in press) and weren't expecting concrete beneficial consequences of their behavior. The fact that they took over behaviors from a TV screen is strong support for the idea that mood has consequences on an automatic behavioral level.

A question that needs to be addressed in future research is how exactly mood moderates mimicry. What processes underlie this effect? A tentative theoretical explanation may be derived from recent theories in the domain of self-regulation and behavior regulation (see, e.g., Kuhl, 2000; Strack \& Deutsch 2002). Strack and Deutsch (2002) proposed a dual system model in which behavior is either (indirectly) instigated by consciously formed intentions or by largely unconscious intuitive mechanisms in response to internal and external cues. Interestingly, Kuhl's (2000) personality systems interaction model suggests that positive mood facilitates the instigation of intuitive behaviors, while negative mood tends to inhibit such behaviors. Although these theoretical accounts are fairly recent and to some extent rather tentative in nature, they would accommodate our present findings. In line with these approaches, we propose that diffuse affect (positive and negative mood) serves a regulatory function both with regard to informa- 
tion processing style and behavioral control (see for an extensive discussion of the model Van Knippenberg, Holland, \& Van Baaren, 2003). With regard to processing style, we propose that negative mood is conducive of conscious, deliberative information processing accompanied by a narrow focus of attention, while a positive mood fosters an intuitive processing style, accompanied by a broad span of attention. Thus, we suggest that positive mood induces a broad span of attention, and an enhanced susceptibility to environmental cues that lay outside the range of the direct focus of attention. Such environmental cues may trigger automatic behaviors (e.g., mimicry). Conversely, in a negative mood the sensitivity for and responsiveness toward such peripheral environmental cues tend to be reduced and, hence, behaviors potentially associated with such cues will be reduced as well (cf. Kuhl, 2000; Van Knippenberg et al., 2003).

Although we have not included specific mediational variables in our present study, some data gathered at the end of the second experiment may provide some preliminary evidence concerning the proposed mediational role of attentional focus. In the room in which the experiment took place, several irrelevant objects were present (e.g., clock, video case, woorden puppet). After the experiment, participants were taken to another room in which they did a surprise memory test (a free recall task and a separate recognition test) to check whether they remembered the objects in the experimental room. In an attempt to reconstruct the participants' attention during the experiment, we computed a "peripheral memory index" by dividing the total number of objects correctly remembered by the time needed to complete the memory task. This index was constructed in order to measure memory, while controlling for effort (conceptually similar to a correction for speed-accuracy tradeoff in Reaction Time tasks). As a first step in the mediation, the effect of mood on the mediator (memory index) was assessed and results indicated that participants in a positive mood condition had better memory of peripheral objects $(M$ $=0.028)$ than participants in the negative mood condition $(M=$ $0.018), F(1,31)=6.90, p<.02$. When the effect of mood on mimicry was controlled for memory, there was no longer a difference in mimicry between the negative and positive mood condition, $F(1$, 
$28)=0.87, n s$. A Sobel test for mediation indicated that the mediation is significant, Sobel's $t=2.26, p<.03$. $^{3}$

This tentative analysis suggests that the effect of mood on mimicry may have been partially mediated by the participant's attentional focus. Participants in a positive mood seem to have processed their surroundings with a broad focus (Friedman, Fishbach, Förster, \& Werth, 2003) including peripheral stimuli that lay outside the range of directly task-relevant stimuli, while participants in the negative mood condition seem to have shielded off such peripheral influences. The finding that processing style influences mimicry is in line with recent research by Van Baaren et al. (2004) where in three studies, a relation between processing style and mimicry was demonstrated. Obviously, more research is needed to gain insight into the underlying processes by which mood affects our non-conscious behavior.

Our moods reflect the valence of our environment (Chartrand, Van Baaren, \& Bargh, in press), which subsequently influences the way in which we perceive and interact with our environment. When our mood signals safety, we adopt a broad span of attention and our behavior becomes subject to subtle environmental influences. Conversely, when our mood signals problems, we tend to adopt a narrow focus of attention and the influence of peripheral environmental cues on our behavior will be reduced.

Future studies should be aimed at further understanding the behavioral consequences of mood and the cognitive and motivation processes involved. For example, is a positive mood also associated with greater behavioral priming (Bargh, Chen, \& Burrows, 1996; Dijksterhuis \& Van Knippenberg, 1998)? In doing so, we will learn more about the subtle ways in which we, as hu-

3. We also performed a mediation analysis using the recognition measure without controlling for effort (not divided by the time it took). As a first step in the mediation, the effect of mood on the mediator (recognition) was assessed and results indicated that participants in a positive mood condition had better memory of peripheral objects $(M=8.29)$, than participants in the negative mood condition $(M=7.38), F(1,31)=4.77, p<.04$. When the effect of mood on mimicry was controlled for recognition, there was no longer a significant difference in mimicry between the negative and positive mood condition, $F(1,28)=2.72, p=11$. A Sobel test for mediation indicated that the mediation was marginally significant, Sobel's $t=1.69, p=.09$. 
man beings, react to our environment, which, from an adaptive point of view, is extremely important for our survival.

\section{REFERENCES}

Bargh, J. A., Chen, M., \& Burrows, L. (1996). Automaticity of social behavior: Direct effects of trait construct and stereotype activation on action. Journal of Personality and Social Psychology, 71, 230-244.

Bless, H., Bohner, G., Schwarz, N., \& Strack, F. (1990). Mood and persuasion: A cognitive response analysis. Personality and Social Psychology Bulletin, 16, 331-345.

Bless, H., Clore, G.L., Schwarz, N., Golisano, V., Rabe, C., \& Wolk, M. (1996). Mood and the use of scripts: Does a happy mood really lead to mindlessness? Journal of Personality and Social Psychology, 71, 665-679.

Bless, H., Mackie, D., \& Schwarz, N. (1992). Mood effects on encoding and judgmental processes in persuasion. Journal of Personality and Social Psychology, 63, 585-595.

Bodenhausen, G., Kramer, G., \& Süsser, K. (1994). Happiness and stereotypic thinking in social judgment. Journal of Personality and Social Psychology, 66, 621-632.

Chartrand, T. L., \& Bargh, J. A. (1999). The chameleon effect: The perception-behavior link and social interaction. Journal of Personality and Social Psychology, 76, 893-910.

Chartrand, T. L., Van Baaren, R. B., \& Bargh J. A. (in press). Consequences of automatic evaluation for mood and stereotyping. Journal of Experimental Psychology: General.

Clore, G. L., Gasper, K., \& Garvin, E. (2001). Affect as information. In J. P. Forgas, (Ed.), Handbook of affect and social cognition (pp. 121-144). Mahwah, NJ: Erlbaum.

Dijksterhuis, A., \& Van Knippenberg, A. (1998). The relation between perception and behavior or how to win a game of Trivial Pursuit. Journal of Personality and Social Psychology, 74, 865-877.

Forgas, J. P. (2002). Feeling and doing: Affective influences on interpersonal behavior. Psychological Inquiry, 13, 1-28.

Friedman, R. S., Fishbach, A., Förster, J., \& Werth, L. (2003). Attentional priming effects on creativity. Manuscript under review.

Gasper, K., \& Clore, G.L. (2002). Attending to the big picture: Mood and global versus local processing of visual information. Psychological Science, 13, 34-40.

George, J. M. (1990). Personality, affect, and behavior in groups. Journal of Applied Psychology, 74, 317-324.

Jacobsen, E. (1957). Normal and pathological moods: Their nature and function. In R. S. Eisler, A. F. Freud, H. Hartman, \& E. Kris (Eds.), The psychoanalytic study of the child (pp. 73-113). New York: International University Press. 
Kuhl, J. (2000). A functional-design approach to motivation and self-regulation: The dynamics of personality systems interactions. In M. Boekaerts, P.R. Pintrich, \& M. Zeidner (Eds.), Handbook of self-regulation. San Diego, CA: Academic Press.

Schwarz, N. (1990). Feelings as information: Informational and motivational functions of affective states. In E. T. Higgins \& R. M. Sorrentino (Eds.), Handbook of motivation and cognition: Foundations of social behavior (Vol 2; pp. 527-561). New York: Guilford.

Schwarz, N., \& Bless, H. (1991). Happy and mindless, but sad and smart? The impact of affective states on analytic reasoning. In J. Forgas (Ed.), Emotion and social judgments (pp. 55-71). Oxford: Pergamon.

Schwarz, N., \& Bohner, G. (1996). Feelings and their motivational implications: Moods and the action sequence. In J. A. Bargh \& P. Gollwitzer (Eds.), The psychology of action: Linking thought and motivation to behavior (pp. 119-145). New York: Guilford.

Schwarz, N., \& Clore, G. (1996). Feelings and phenomenal experiences. In E. T. Higgins \& A. W. Kruglanski (Eds.), Social psychology: Handbook of basic principles (pp. 433-465). New York: Guilford.

Strack, F., \& Deutsch, R. (2002). Reflective and impulsive determinants of social behavior. Manuscript under review.

Van Baaren, R. B., Horgan, T. G., Chartrand, T. L., \& Dijkmans, M. (2004). The forest, the trees and the chameleon: Context-depenency and mimicry. Journal of Personality and Social Psychology, 86, 453-459.

Van Baaren, R. B., Maddux, W. W., Chartrand, T. L., De Bouter, C., \& Van Knippenberg, A. (2003). It takes two to mimic: Behavioral consequences of self-construals. Journal of Personality and Social Psychology, 84, 1093-1102

Van Knippenberg, A., Holland, R. W., \& Van Baaren, R. B. (2003). Self-regulatory processes: Towards an integrative model. Unpublished manuscript, University of Nijmegen, The Netherlands. 